\title{
El sentimiento de exclusión
}

\author{
Guillaume le Blanc \\ Traducción del francés al español de Luis Alfonso Paláu-Castaño \\ Universidad Nacional de Colombia, Medellín, Colombia \\ lapalau@gmail.com
}

¿Qué es un hooligan? ¿Un desraizado, un no-alineado, un marginal? ¿Un exiliado?

(Norman Manea, 2005)

¿Por qué tenemos en la actualidad el sentimiento de estar a este punto excluidos? Siempre es posible decir que la exclusión es una ficción, que en realidad cada vez somos sujetos más integrados. ¿No es nuestra vida materialmente mejor que la de nuestros padres? Sin embargo, la angustia de vivirse por fuera nunca ha sido tan grande. En lo más profundo de las vidas psíquicas está el espectro del sin-domicilio fijo, el sentimiento último de la caída, la inquietud de hundirse. Como lo señala el escritor Bernard Chambaz (2011), "en todas las lenguas, caer, por extensión, es morir" (p. 18). Con el temor de ser desembarcado, es claramente de nuestra vulnerabilidad de lo que se trata. Vulnerabilidad social ante todo pues ya no estamos agarrados por ningún hilo de humanidad, porque entonces "todo terminó, sin que se [nos] haya dado el derecho de comenzar, de decidir comenzar" (Djavann, 2004, p. 7). Vulnerabilidad psíquica luego porque el espíritu está en suma precariedad, obligado a darse vuelta permanentemente sobre la negación que lo absorbe, lo traga.

Sin embargo, el sentimiento de exclusión significa igualmente que las vidas experimentan la injusticia y que ellas son capaces de cortar su nudo refiriéndola al valor de la justicia y de no quedarse por ello en la constatación de una vulnerabilidad excesiva. Si da testimonio del valor social de las vidas, igualmente revela que las vidas son portadoras de voces que rebasan ese valor social, pues ellos vienen a percibir la vulnerabilidad inherente a la vida en la ciudad. Allá donde la ciudad se encierra sobre su orden social, político y económico, voces se levantan que se rehúsan a reducirse a un tal orden y nos obligan a ampliar

Cómo citar: Le Blanc, G. (2020). El sentimiento de exclusión. Ciencias Sociales y Educación, 9(17), 281-286. https://doi.org/10.22395/csye.v9n17a13

Traducción realizada por Luis Alfonso Paláu-Castaño. Agradecemos a la editorial Bayard por permitir el acceso del libro en francés para su versión parcial en español. Se conserva la presentación editorial del francés. Nota del editor.

Recibido: 10 de febrero de 2020.

Aprobado: 16 de marzo de 2020. 
el derecho de ciudad poniéndole atención a las vidas excluidas. En el Séptimo hombre, el escritor John Berger, ayudado por las fotografías de Jean Mohr, relata el destino de los trabajadores inmigrantes a Europa, de su improbable éxodo hasta su regreso, no menos improbable, hacia sus países de origen. Es un hecho que de esas vidas precarias salidas de las antiguas colonias (antillanos, paquistaníes, hindúes, argelinos, etc.) no sabemos nada. Como tampoco sabemos de todas esas vidas excluidas. Allí donde ese no-saber puede ser objeto de una denegación suplementaria, el sentimiento de la exclusión, que es claramente nuestra angustia de ser o de no ser, nos lleva a esas vidas excluidas, deja entrever un común que ninguna violencia política, económica o social puede borrar totalmente. No se trata de una pertenencia sólida susceptible de mudarse en plataforma de reivindicaciones, sino el sentimiento de una frágil humanidad que ninguna autoridad, cualquiera sea su naturaleza, puede en absoluto borrar. El sentimiento de exclusión es entonces lo irreductible de la vida humana que persiste hasta en la ausencia de todo lugar. El excluido es, a la manera del emigrado, un ser de ninguna parte, pero cuya borradura remite a nuestra posible ausencia de todas partes. Desde entonces, las clasificaciones para hacerlo entrar, a pesar de todo, en las lógicas económicas y sociales del mundo contemporáneo no logran borrar esta ausencia de lugar. Al interesarse en la trayectoria del inmigrante, Berger y Mohr (2009) anotan:

Una tal salida puede ser clasificada en muchas categorías generales para lograr normalizarla: la vía del desarrollo, la unificación de Europa, la historia del capitalismo, e incluso la lucha revolucionaria que se anuncia. Pero estas categorías no le devuelven su patria. En el espacio y el tiempo. (p. 237)

A los excluidos se los busca reintegrar en las diferentes justificaciones de la ciudad, pero ellos escapan y con ellos es claramente la referencia a la normalidad la que se atasca. Porque no tener sitio, no tener lugar, dada la necesidad de desplazarse, es terminar interrogando el orden de la ciudad que produce el lugar de los unos y la ausencia de lugar de los otros. Un mundo donde no hay lugar para todo el mundo ¿será aún un mundo? El sentimiento de exclusión que es compartido en la actualidad casi por todas las vidas, a causa de la escasez de lugares (Lussault, 2009) y de su precariedad vincula, sin embargo, las vidas las unas a las otras. $Y$ nos reconocemos cada uno a nuestra manera como vulnerables, como expuestos a todas las formas de violencia, física, social y psíquica; damos un paso hacia una comprensión de la exclusión como una cosa común más bien que como el único asunto de los excluidos.

Por un lado, estamos cada vez más absorbidos por los imperativos económicos de la ciudad; nunca habíamos sido tan exigidos para producir y consumir (Lister, 2004, p. 26), y esto supone que las normas sociales y culturales que condicionan nuestras necesidades fundamentales adquirieron cada vez más poder 
para hacer inteligibles las vidas humanas a la luz de sus mensajes subliminales. Por otro lado, estamos cada vez más precarizados en la ciudad y nuestras vidas se nos aparecen como cada vez más frágiles. ¿Qué podemos hacer con esta fragilidad? ¿La podemos devolver contra los presupuestos autoritarios de la ciudad y hacerla jugar como una autoridad alternativa? Esta pregunta resume el propósito de este libro. ¿Se puede considerar que exista una potencia de actuar de los "sin-poder" susceptible de cuestionar lo que se espera de la ciudadanía jurídica, social, política y económica, que garantizan un orden de la ciudad particularmente hegemónico? En su ensayo consagrado a Antígona, la filósofa Judith Butler señala que Antígona, al rehusar la orden de Creón de no enterrar a su hermano, ciertamente "no solo porque desafía a la ley sino también porque se apropia de la voz de la ley para cometer un acto en contra de la ley misma" (Butler, 2001, p. 26). Antígona terminará por ser excluida de la ciudad, pues ella se opondrá al orden simbólico que excluye a su hermano de la comunidad de los humanos dignos de ser enterrados. Pero esta exclusión lleva en sí misma el índice de un rechazo de la ley que incluye/excluye en provecho de una pretensión a ser igualmente la "voz de la ley". Y este es el punto más importante: los excluidos no son sujetos negativos que esperan solamente ser puestos sobre sus rieles. Ellos tienen una voz que discute el privilegio de la ley que incluye a los unos, para excluir a los otros. Es esta voz la que atraviesa los movimientos sociales, políticos por los que las vidas llegan a reconsiderar lo que las liga a la ciudad. El sentimiento de exclusión que agarra por el cuello a una vida, incluso cuando esta no está excluida, da testimonio de una humanidad más vasta que la ciudad y también de la posibilidad de una comunidad de vidas hasta en la experiencia de la exclusión. Entonces necesitamos decir esto: el excluido, en su invisibilidad real, en su supuesta peligrosidad; el ausente de los lugares y de las clasificaciones, por la persistencia de su voz y de su actuar, interroga el curso normal presunto de las cosas. En particular, al recusar estar del lado de la patología, al criticar la definición del excluido como un "enfermo", nos obliga, a partir de la aceptación de un fondo de vulnerabilidad común, a interrogarnos sobre lo que hoy constituye mundo, y sobre nuestra capacidad de abrirlo a aspectos de la vida bien diversos sin llegar por ello a legitimar la exclusión de los excluidos, considerándola como un mal necesario o un daño colateral.

Los excluidos de hoy tienen mala prensa. ¿Más que ayer? Se les achaca todo tipo de males. Ora son malos trabajadores que prefieren vivir de las migajas oficiales que encontrar un empleo. Ora son malos extranjeros que no quieren integrarse. O son mujeres dudosas, demasiado veladas como para ser honestas. O desplazados atolondrados que no saben asentarse. Y todo ese nuevo pueblo del margen es una gran familia. Hay primos, tíos, tías, abuelas, o son desplazados, la escoria, emigrantes indocumentados, sin domicilio conocido, desempleados que sin duda no tienen gran cosa en común, pero que son enrolados en la categoría 
de los "excluidos". Poco importa saber si los propios excluidos reivindican esta categoría como pertinente. Parece que esta sea una violencia suplementaria que surge a partir de una experticia que no les pertenece, en la que les es incluso prohibido participar, excepto bajo la forma discutible de población-objetivo en los registros de las hipótesis, pensamientos y diagnósticos producidos por científicos que no pertenecen precisamente al mundo de los excluidos. Los excluidos tienen la palabra solamente en la medida en que ellos confirmen su exclusión, en que ellos suscriban los estereotipos que los comprenden como seres solamente de carencias que tienen que llegar a hacer un esfuerzo para salir adelante. Pues está implícito que ellos, o no hacen esfuerzos, o no son suficientes o no en el buen sentido. El excluido tiene rabia evidentemente, y esa rabia no va a ninguna parte. Es un muro opuesto a otro muro.

Por un lado, los excluidos siempre son identificados demasiado rápidamente. O bien son más que todo sujetos considerados como inútiles, que estorban, que no se sabe qué hacer con ellos. O bien son sujetos que se los tiene por peligrosos de los que hay que desconfiar, que hay que administrar por medio de dispositivos disciplinares renovados. Por el otro lado, a los excluidos frecuentemente se los invisibiliza. No se los escucha, ya no se los quiere ver. Solo pueden existir como espectros, vidas a la espera de confirmación pero que deben enterrarse, ocultarse. Estas dos consideraciones de la exclusión pueden parecer contradictorias al punto que la primera establece una ficha señalética del excluido, mientras que la segunda se esfuerza por sacarlo de todos los campos de percepción. En realidad, en esto consiste la ambigüedad del tratamiento social, antropológico y político de la exclusión. Son dos elementos de un dispositivo en el que el excluido es visto como un humano que no es como los otros, en los bordes de lo social y amenazador, peligroso y potencialmente ausente. Según este dispositivo, el excluido está en la ciudad y por fuera de ella, es un elemento supernumerario con el que no se sabe qué hacer y que es necesario entonces (en el mejor de los casos) hacerlo invisible, así como hay que poner cuidado que no vaya a perturbar el orden público.

¿Pero, quién se oculta tras este dispositivo? Todos nosotros, en nuestras vidas ordinarias, pertenecemos a este dispositivo, lo hacemos prosperar. Cada vez que volteamos a mirar para otra parte cuando somos interpelados por un "indigente", cada vez que construimos un muro entre "ellos" y "nosotros", le damos más impulso, lo alimentamos, nos convertimos en un rodamiento esencial del orden social, del imperativo siempre más actual según el cual "hay que defender la sociedad". Tal parece ser claramente el tratamiento social de la exclusión hoy: más bien se tiende a "defender la sociedad" de los excluidos que defender una sociedad de los excluidos, es decir, reiterar el orden social con respecto a y a pesar de todo, antes que querer ampliar el mundo común buscando comprender, 
por una parte, por qué los excluidos están excluidos y, por otra parte, penetrar en la potencia de actuar de las vidas excluidas.

¿Podemos ampliar nuestra comprensión de lo humano más allá de las fronteras sociales que producen un "adentro" y un "afuera"? ¿Podemos imaginar que la vida humana no se limita a una vida humana integrada? Para ello no es suficiente con hablar en nombre de los otros, representarlos, sino que es necesario igualmente ampliar el derecho de ciudad, encararlo, no como un derecho exclusivo, sino como el derecho de toda vida al pleno de desarrollo, tanto en su poder interior como en su poder exterior, en la ciudad, reformulándola en sus normas sociales, políticas, jurídicas, antropológicas. Es necesario entonces repensar la ciudadanía de los excluidos. Dos condiciones se revelan desde entonces necesarias. Que ella sea igualmente una ciudadanía social que integre los derechos sociales en su formulación al lado de los derechos civiles. Que la ciudadanía sea igualmente resignificada desde los procedimientos de exclusión que no afecten en nada las vidas por azar. Pues la exclusión, si puede llegar frecuentemente de manera accidental, no por ello es un accidente de la vida social. La exclusión es el reverso de la inclusión. La inclusión de los unos no parece posible sino gracias a la exclusión de los otros. Si tal es el caso, es toda la ciudad, es todo nuestro mundo el que está concernido por ella. ¿Por qué vivimos en un mundo que no puede incluir a los unos sino excluyendo a los otros? ¿Quiere esto decir que no hay trabajo para todo el mundo? ¿Es decir que no hay lugar para toda la gente? ¿Pero qué puede ser un mundo donde la posibilidad de la caída está a tal punto no circunscrita?

Creíamos haber terminado con los excluidos. Eminentes personalidades nos habían casi convencido de la inexistencia de esa categoría; demasiado comodín, en exceso abigarrada, mezclando voces heterogéneas, trayectorias distintas. Y es verdad: ¿qué idea es esa de interesarse a la vez en el desempleado, el trabajador precario, el inmigrante, la mujer dominada, el solicitante de asilo? Es seguramente exponerse a numerosas ilusiones, típicamente las que engendran los filósofos con sus tópicos mal construidos, cosidos en trajes demasiado holgados para la mirada de algunos expertos del mundo social. ¿Pero debe ser la experticia la última palabra en el mundo social? ¿En este caso no se corre el riesgo de que estemos siempre demasiado del lado de los gobernantes y no suficientemente del lado de los gobernados? Acá estriba la dignidad de la categoría de excluido; obliga a reconsiderar lo que actualmente constituye el pueblo, obliga a volverle a dar sentido a un pueblo de los miserables y a penetrar desde entonces, casi por la fuerza, en una serie de cuestiones prohibidas relativas a la ontología social que subyace a nuestro mundo común. Durante mucho tiempo nos hemos mantenido a distancia de esas interrogaciones, pues terminamos por aceptar el escepticismo que manifestaban los gobernantes con respecto a 
las clases populares, a las que se identificó con demasiada ligereza con clases peligrosas. Si esta desconfianza con respecto a las clases populares es tal actualmente que hay mujeres y hombres políticos que pueden estar tentados a considerar que ellas no forman ya el corazón del blanco de su electorado (como lo ha podido aún ilustrar recientemente un reporte de Terra Nova), entonces hay que apostar a que las clases populares mismas terminarán por afirmarse cada vez más en la desconfianza con respecto al mundo político tradicional, ya sea alejándose de él totalmente (especialmente por el fenómeno de la abstención), ya sea buscando en las extremas una alternativa para hacer creíbles sus formas de vida. Solo reconociendo que somos vulnerables podremos afrontar la exclusión y comprenderla, a pesar de todo, como una posibilidad humana y también como una posibilidad de vida humana.

\section{Referencias}

Butler, J. (2001). El grito de Antígona. El Roure.

Berger, J. y Mohr, J. (2009). El séptimo hombre. Surt.

Chambaz, B. (2011). Plonger. Gallimard.

Djavann, C. (2004). Autoportrait de l'autre. Sabine.

Le Blanc, G. (2011). Le sentiment d'exclusion. En G. le Blanc (dir.), Que faire de notre vulnérabilité? (pp. 9-23). Bayard.

Lister, R. (2004). Poverty. Polity Press.

Lussault, M. (2009). De la lutte des classes à la lutte des places. Grasset.

Manea, N. (2005). El regreso del húligan. Tusquets. 